\title{
Standardized Ear Acupuncture and Settings Assuring Flexible Ties in Psychiatry
}

\author{
Summa-Lehmann $\mathrm{P}^{*}$ \\ Westphalian Psychotherapy, Weeks Hattingen, Germany
}

Submission: February 10, 2017; Published: August 09, 2018

*Corresponding author: Summa-Lehmann P, Westphalian Psychotherapy, Weeks Hattingen, Germany; Email: dr.summalehmann@gmail.com

\begin{abstract}
Summary
The transtheoretical change model [1] which is very common in the field of addiction treatment, is related to the „NADA protocol“ [2]. In case of psych vegetative withdrawal symptoms and in early stages of a willingness to change, the focus is on perceptible relaxation and reduction of symptoms. In later stages, the focus is rather placed on self-perception, emotion regulation and craving. The creation of framework conditions, a helpful relationship and body contact are of particular importance. A stabilizing and adapted approach of standardized ear acupuncture will be represented using the example of trauma-related therapy.
\end{abstract}

Keywords: Ear; Transtheoretical; Symptoms; Craving; Framework; Psychiatric

\section{Introduction}

The demands set on a standardized ear acupuncture (EA) in group setting [2] may be well combined with the requirements of an adjuvant therapy method in psychiatry and psychosomatics. I believe that ear acupuncture according to the NADA protocol is particularly suited for the everyday psychiatric treatment due to the dialectic relationship between standardized ear acupoints and flexible settings. With the flexibilization of the framework conditions, this simple 3-5-combination of points can be individualized and embedded in the respective overall treatment concepts and settings. This will be briefly presented on the basis of two clinical pictures.

\section{Treatment options}

The basis for every treatment of addicted people is a differentiated anamnesis and diagnosis, as well as a differentiated information and instruction of the respective patient regarding the process of the ear acupuncture sessions, safety measures and the discussion on indication. For the implementation and realization of ear acupuncture in group setting, this means a differentiated conceptualization and clear agreements within the team and with the patients.

The process of the ear acupuncture in a group is organized equally by all members of the team and thus transparent to all patients. Thus, it is easier for the patients to orientate their expectations to the really predictable processes and expectations; additionally, it supports the emotional and social safety while considering the need for control in case of individual patients. This is why the ear acupuncturists are trained during their professional training to assume managerial responsibilities of an ear acupuncture session the group setting. In terms of a body- mind-relationship or embodiment [3], a conditioning of psych vegetative processes can take place and an improved perception of relaxation effects can be achieved which makes it easier to bear the actual withdrawal symptoms and it increases the motivation to handle the craving phenomenon. This structured and standardized ear acupuncture can easily embedded in the overall treatment concept and combined with other therapeutic methods. This allows to agree on different targets with the patients, corresponding to motivation phases and approaches, within the framework of TTM and also to support them with ear acupuncture. Examples for possible interventions regarding the respective motivational phase:

a) Precontemplation: development of a personal relationship, short-term intervention, information, offering a participation in EA and validation of really experienced, body-related effects e.g. in a basic treatment.

b) Contemplation: use the effects of experienced EA in order to strengthen the willingness to change and the confrontation with craving.

c) Preparation: develop the target hierarchy. foster and stabilize the self-perception

d) Action: foster the cognitive, physical and emotional perception and reflection and connect it with concepts to prevent relapses. Improve the capacity to act and the capacity to change, identify cues for craving and foster awareness with EA.

e) Maintenance: foster self-efficacy, emotional experience, early detection markers, relapse prevention, empowerment. 
The clinical picture of a posttraumatic stress disorder which is characterized e.g. by flash backs, increased psychic sensitivity and excitation, hypervigilance, sleep disturbances, the setting variables of the ear acupuncture have to be modified specifically. This requires a well-coordinated and methodically clear treatment planning and target orientation within the treatment team. Embedded in a trauma-therapeutically overall concept, the social group becomes an „external safe location “, with a safe place and a transparent controllable method. The acupuncturist -as the contact person- stays in the group room during the overall process of EA sessions and assures interpersonal protection. With the help of agreed stop signals, the process can be terminated directly, and additionally, the overexcitation may be reduced and regressive processes may be limited with the help of breathing mindfulness.

\section{Five Phases}

Mindful ear acupuncturists can organise the individual 5 phases of the overall process (in group setting) in an individual and flexible manner. In the first phase, the indication of treatment, basic information, the information on and consent to this treatment, the patient is asked of his/her the expectations and cognition attitudes and a consensus is generated on possible effects and individual expectations of impact. The second phase includes the placing of the needles with a safe needle insertion technique and control of the relationship between closeness and distance. In the third phase, the silence (sometimes accompanied by music with natural sounds), a neuro physiologically generated relaxation response will be enabled. Repetition can result in a faster conditioning. The fourth phase -when the needles are drawn out- is a phase of control, confirmation, reassurance, and unclear phenomena are clarified briefly. In the fifth phase -the mutual discussion- all participants have the opportunity to exchange on their experiences. The basic attitude of the ear acupuncture therapist is characterized by respect, acceptance, presence, attention and empathy.

\section{Future Prospects}

This article includes the representation of the importance of the disorder-specific modifications of setting variables for a standardized ear acupuncture by means of two examples. Previous experiences and publications show that ear acupuncture is an effective component in a body- and mind-related multimodal complex therapy. Another example is a publication regarding EA in case of Major Depression [4].

\section{References}

1. Prochaska JO, Di Clemente CC (1982) Towards a comprehensive model of change. In: Treating addictive behaviors. In: Miller WR, Heather $\mathrm{N}$ (Eds.) New York, USA, Pp. 3-27.

2. Röbe A (2015) Standardisierte Gruppenohrakupunktur nach dem NADA-Protokoll bei allgemeinpsychiatrisch erkrankten Patienten einer Schweizer Tagesklinik Dt Ztschr f Akup. 58(2): 6-9.

3. Tschacher W, Storch M. Die Bedeutung von Embodiment für Psychologie und Psychotherapie. Psychotherapie 2012 Bd. 17, Heft 2: 259-267.

4. Geib J, Rieger MA, Stefanie J, Eschweiler GW, Thomas Dresler, et al. (2015) Introduction of Auricular Acupuncture in Elderly Patients Suffering from Major Depression: Protocol of a Mixed Methods Feasibility Study. BioMed Research International 215: 1-6.

Your next submission with Juniper Publishers
will reach you the below assets
- Quality Editorial service
- Swift Peer Review
- Reprints availability
- E-prints Service
- Manuscript Podcast for convenient understanding
- Global attainment for your research
- Manuscript accessibility in different formats
( Pdf, E-pub, Full Text, Audio)
- Unceasing customer service
Track the below URL for one-step submission
https://juniperpublishers.com/online-submission.php

